\title{
ИЗ ПРАКТИКИ
}

\section{КЛИНИЧЕСКОЕ НАБЛЮДЕНИЕ ПАЦИЕНТА-НАРКОКУРЬЕРА С ОСТРЫМ ОТРАВЛЕНИЕМ ГЕРОИНОМ}

В.В. Шилов ${ }^{1}$ В.А. Лукин ${ }^{2}$, В.Е. Савелло А.М. Антонова ${ }^{2}$, Л.П. Пивоварова ${ }^{2}$, И.В. Осипова ${ }^{2}$, А.В. Рикова ${ }^{2}$, С.С. Гайдук ${ }^{2}$

${ }^{1}$ ФГБОУ ВО «Северо-Западный государственный медицинский университет им. И.И. Мечникова", 195015, г. Санкт-Петербург, Российская Федерация. ${ }^{2}$ Государственное бюджетное учреждение "СанктПетербургский Научно-исследовательский институт скорой помощи им. И.И. Джанелидзе", 192242, г. Санкт-Петербург, Российская Федерация

$D$ статье приводится описание клинического наблюдения пациента-наркокурьера, перевозившего контрабандным путем в полости желудка контейнеры, наполненные героином и поступившего в многопрофильный стационар в результате развившегося у него острого отравления. Острое отравление развилось в результате самопроизвольного нарушения целостности контейнера и излияния его содержимого в полость желудка. В стационаре проведена диагностика и комбинированное лечение - хирургическое вмешательство и детоксикация. Приведены результаты клинических, лабораторных и инструментальных исследований, а также результаты лечения.

Ключевые слова: героин, системное воспаление, хирургическое лечение.

Героин как полусинтетическое наркотическое средство опиоидной природы в настоящее время поставляется на территорию Российской Федерации и используется нелегальным путем. В последнее время перевозчики помимо типичных мест сокрытия наркотических веществ (ручная кладь, бытовые предметы, оборудованные тайниками и др.) часто используют так называемый внутриполостной способ сокрытия, когда наркотические вещества перевозятся внутри человеческого тела. В большинстве случаев такой способ сокрытия используется при осуществлении незаконных перевозок наркотиков на воздушном транспорте, так как время, затраченное на перевозку, имеет важное значение для наркокурьера. Перевозка наркотиков внутриполостным путем обеспечивает сравнительно малую вероятность их обна- ружения, но одновременно является сложным и опасным способом транспортировки [1]. Опасность преимущественно связана с разрушением или повреждением целостности контейнера, внутри которого содержится наркотическое вещество с последующим излиянием его в полость органа и развитием интоксикации. Клиническое течение интоксикации героином широко описано в литературе [2, 3, 4]. Подобные отравления опасны развитием инфекционных осложнений. Ранее нами было показано, что при острых отравлениях веществами наркотического действия уже в ранние сроки у больных наблюдаются признаки системной воспалительной реакции, одним из факторов генерализации которой является активация продукции медиаторов воспаления (цитокинов) [5].

Шилов Виктор Васильевич (Shilov Victor Vasilevich), доктор медицинских наук, профессор, заведующий кафедрой токсикологии, экстремальной и водолазной медицины ФГБОУ ВО “Северо-Западный государственный медицинский университет имени И.И.Мечникова", г. Санкт-Петербург, Российская Федерация, vshilov@inbox.ru

Лукин Вадим Анатольевич (Lukin Vadim Anatolevich), кандидат медицинских наук, заведующий отделением токсикологии НИИ скорой помощи им. И.И.Джанелидзе, г. Санкт-Петербург, Российская Федерация, Vadim.Lukin@mail.ru

Савелло Виктор Евгеньевич (Savello Victor Evgenevich), доктор медицинских наук, профессор, руководитель отдела лучевой диагностики ниИ скорой помощи им. И.И.Джанелидзе, г. Санкт-Петербург, Российская Федерация, prof savello@emergency.spb.ru

Антонова Анна Михайловна (Antonova Anna Mychailovna), кандидат медицинских наук, заведующая отделением рентгенологии НИИ скорой помощи им. И.И.Джанелидзе, г. Санкт-Петербург, Российская Федерация, ama-spb@yandex.ru

Пивоварова Людмила Павловна (Pivovarova Ludmila Pavlovna), доктор медицинских наук, руководитель отдела лабораторной диагностики ГБу «СПб ниИ скорой помощи им. И.И.Джанелидзе", 192242, г. Санкт-Петербург, Российская Федерация, pivovaroval@yandex.ru

Осипова Ирина Викторовна (Osipova Irina Viktorovna), кандидат медицинских наук, заведующая лабораторией иммунологии ГБУ «СПб НИИ скорой помощи им. И.И.Джанелидзе", 192242, г. Санкт-Петербург, Российская Федерация

Рикова Анна Владимировна (Rikova Anna Vladimirovna), заведующая клинико-диагностической лабораторией ГБУ “СПб НИИ скорой помощи им. И.И.Джанелидзе», 192242, г. Санкт-Петербург, Российская Федерация, kdInii@yandex.ru

Гайдук Сергей Семенович (Gajduk Sergej Semenovich), кандидат медицинских наук, старший научный сотрудник отдела неотложной хирургии ГБУ «СПб НИИ скорой помощи им. И.И.Джанелидзе»,192242, г. Санкт-Петербург, Российская Федерация, ssgaiduk@rambler.ru 
Собственные наблюдения. Пациент Ш., 24 лет, с целью контрабандной перевозки поместил в полости желудка 100 упаковок (контейнеров), наполненных героином. Во время транспортировки по неустановленной причине произошло нарушение целостности контейнера и содержимое контейнера оказалось в полости желудка. Первые признаки интоксикации проявились после приземления самолета в виде нарушения сознания и дыхания. Прибывшие на место события специалисты скорой медицинской помощи наблюдали угнетение сознания до уровня комы (7 баллов по шкале Глазго) [6], миоз, брадипноэ до 9 раз в минуту.

При поступлении в стационар состояние пациента Ш. тяжелое, сознание на уровне комы (6 -7 баллов по шкале Глазго), миоз с отсутствием реакции на свет, дыхание с помощью мешка Амбу. Нормостеническое телосложение. Периферических отеков нет. Лимфатические узлы не увеличены. Дыхание везикулярное. Хрипов нет. ЧДД - 7 раз в минуту. Артериальное давление 130 и 80 мм. рт. ст. Частота сердечных сокращений 95 ударов в минуту. Живот мягкий. Печень не увеличена. Менингиальных знаков нет. Глазные ще- ли $\mathrm{S}=\mathrm{D}$. Зрачки симметричные, 2 мм в диаметре. Корнеальные рефлексы сохранены.

С целью исключения очагов инфекции и определения наличия инородных тел в организме, проведены рентгенологические исследования органов грудной клетки и брюшной полости.

На обзорной рентгенограмме органов грудной клетки - без инфильтративных изменений.

На обзорной рентгенограмме живота, выполненной в положении пациента лежа, определяются множественные инородные тела (контейнеры с героином) полностью заполняющие желудок и единичные в восходящей ободочной кишке (Рис. 1.)

На обзорной рентгенограмме груди, выполненной в положении пациента лежа: очаговых и инфильтративных изменений в легких не выявлено. Отмечается усиление легочного рисунка за счет сосудистого компонента. Корни легких не расширены, структурны. Сердце расширено в поперечнике за счет левых отделов. (Рис. 2)

На обзорной рентгенограмме живота, выполненной в положении пациента лежа, интраоперационно, определялось 3 инородных тела (контейнера с героином) в восходящей ободочной кишке (Рис. 3).

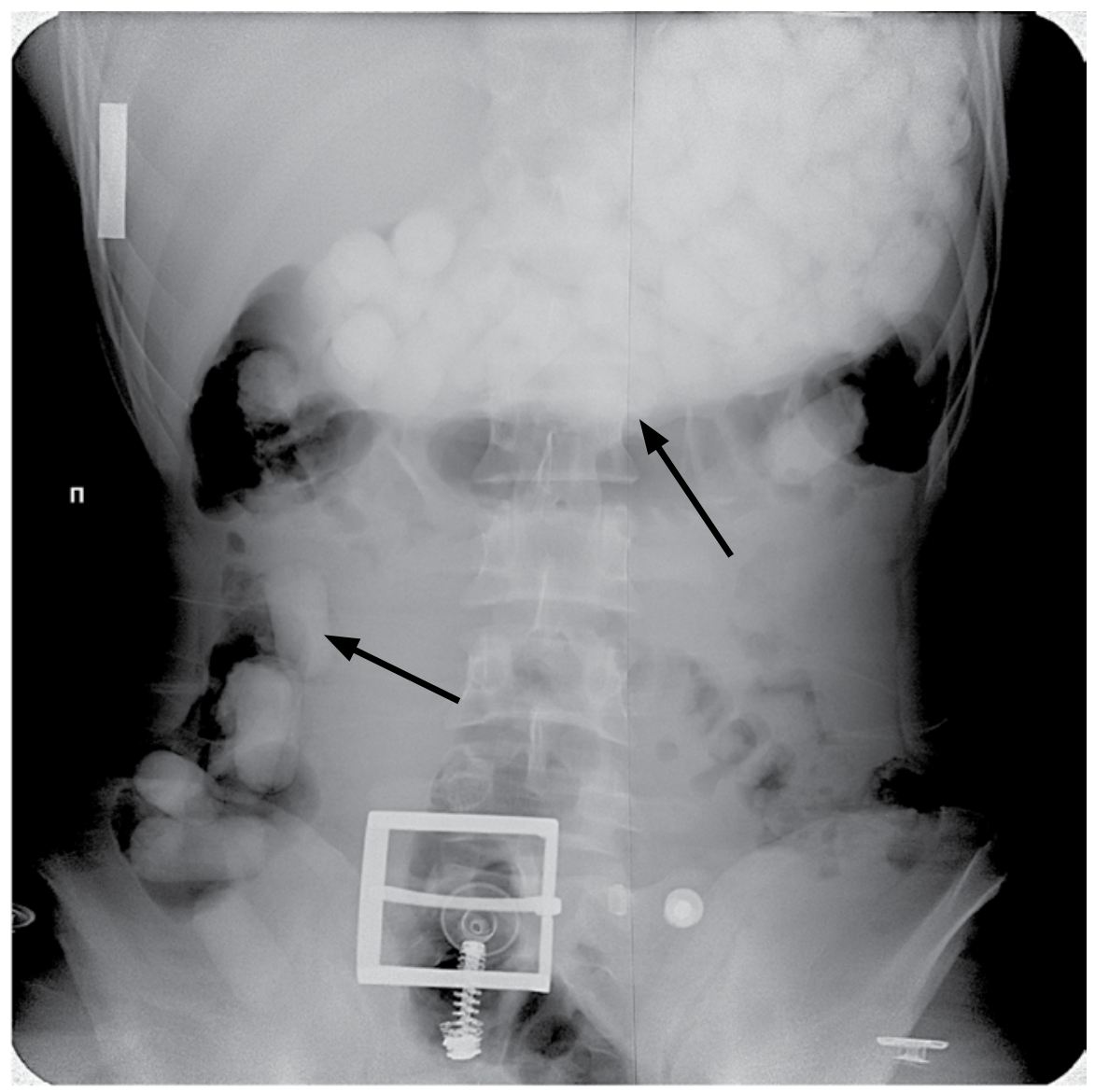

Рис. 1. Пациент Ш., 24 г. Рентгенограмма живота. В проекции желудка и в восходящей ободочной кишке определяются множественные контейнеры с героином (указано стрелкой). 
Диагноз формулировался следующим образом: «Множественные инородные тела желудочно-кишечного тракта. Острое отравление веществом наркотического действия опийной природы тяжелой степени. Острая дыхательная недостаточность. Искусственная вентиляция легких». Диагноз подтвержден химико-токсикологическим исследованием мочи.

С целью извлечения контейнеров больному под эндотрахеальным наркозом (с использованием закиси азота с кислородом в сочетании с нейролептаналгезией) выполнены верхне-средне-срединная лапаротомия, гастротомия, колонотомия с последующей эвакуацией 97 контейнеров из полости желудка и 3 контейнеров из восходящей ободочной кишки. Общий вес извлеченных контейнеров, содержащих вещество наркотического действия, составил 1500 граммов. После извлечения проведено ушивание гастротомического, колонотомического отверстий с послойным наложением швов на лапоротомную рану. Послеоперационное течение гладкое: на вторые сутки больной из реанимационного переведен на общехирургическое отделение, восстановление перистальтики кишки произошло на 3-и сутки, кормление пациента начато на 5-е сутки. Послеоперационные швы сняты на восьмые сутки.

На контрольной рентгенограмме органов брюшной полости после удаления контейнеров с героином инородные тела не выявлены (Рис. 4)

Результаты лабораторных исследований: при поступлении пациента наблюдали лейкоцитоз (11,7 · 109/л, норма от 6 до 8· 109/л); гипоксемию (рО2 77,6 мм рт.ст.; норма от 88,1 до 102,5 мм рт.ст.); гиперлактатемию (лактат 4,3 ммоль/л; норма от 0,8 до 1,7 ммоль/л), увеличение содержания интерлейкина- 6 до 83 пг/мл (норма от 2 до 26 пг/мл), повышение С-реактивного белка до 9 мг/л (норма от 2 до 4 мг/л). Другие исследуемые биохимические показатели (общий белок, билирубин, мочевина, креатинин, аланинаминотрансфераза, аспартатаминотрансфераза, электролиты) были в пределах нормальных значений. В дальнейшем лабораторные исследования проводили в динамике через 1,3 и 5 суток после отравления на фоне проводимой детоксикационной и симптоматической терапии. Показатели содержания кислорода и лактата на фоне проводимой искусственной вентиляции лёгких восстановились через 1 сутки рО2 - 89,7 мм рт. ст., на 5 сутки - 92,8

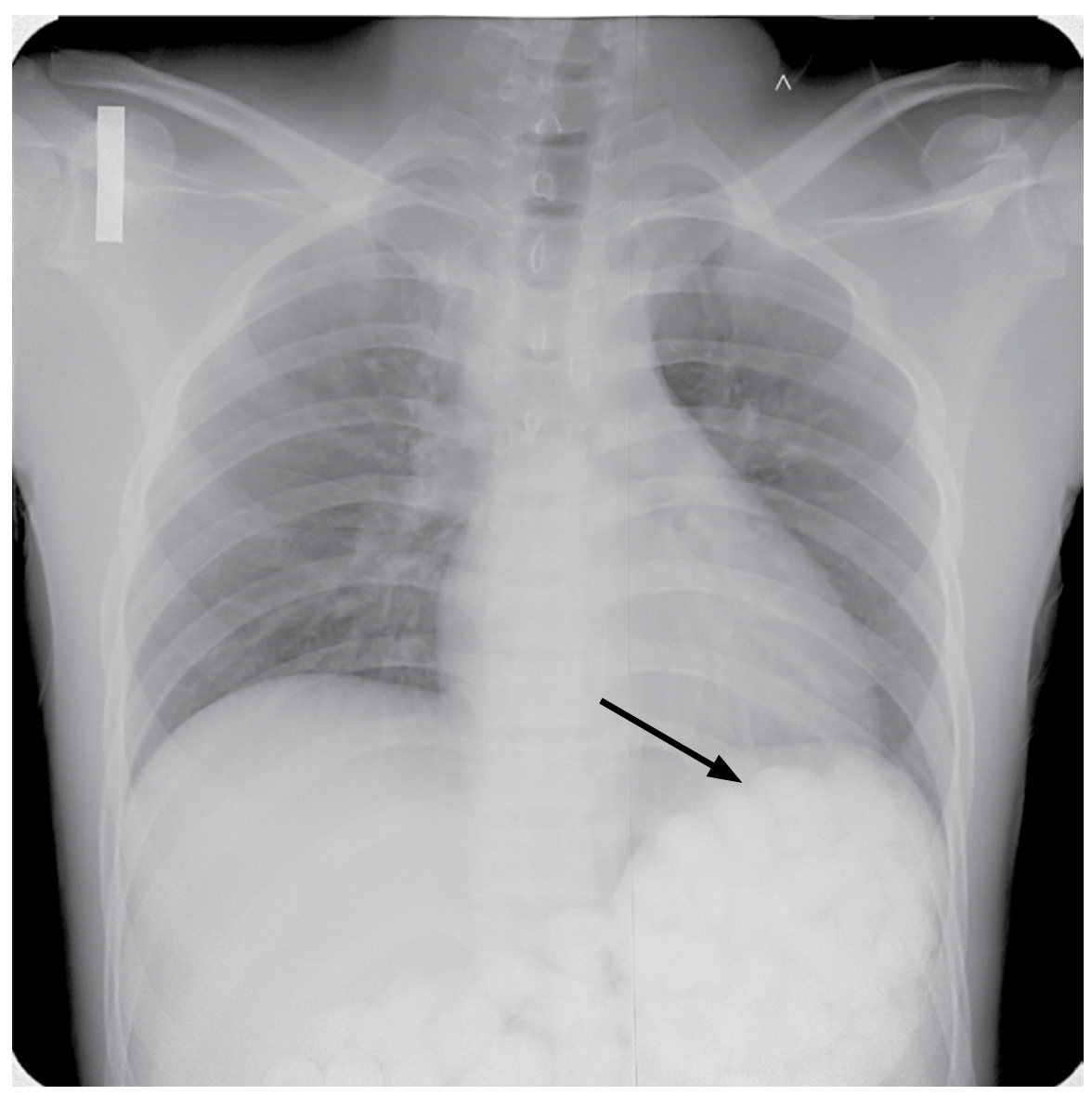

Рис. 2. Пациент Ш., 24 г. Рентгенограмма груди. В проекции желудка определяются множественные контейнеры с героином (указано стрелкой). 


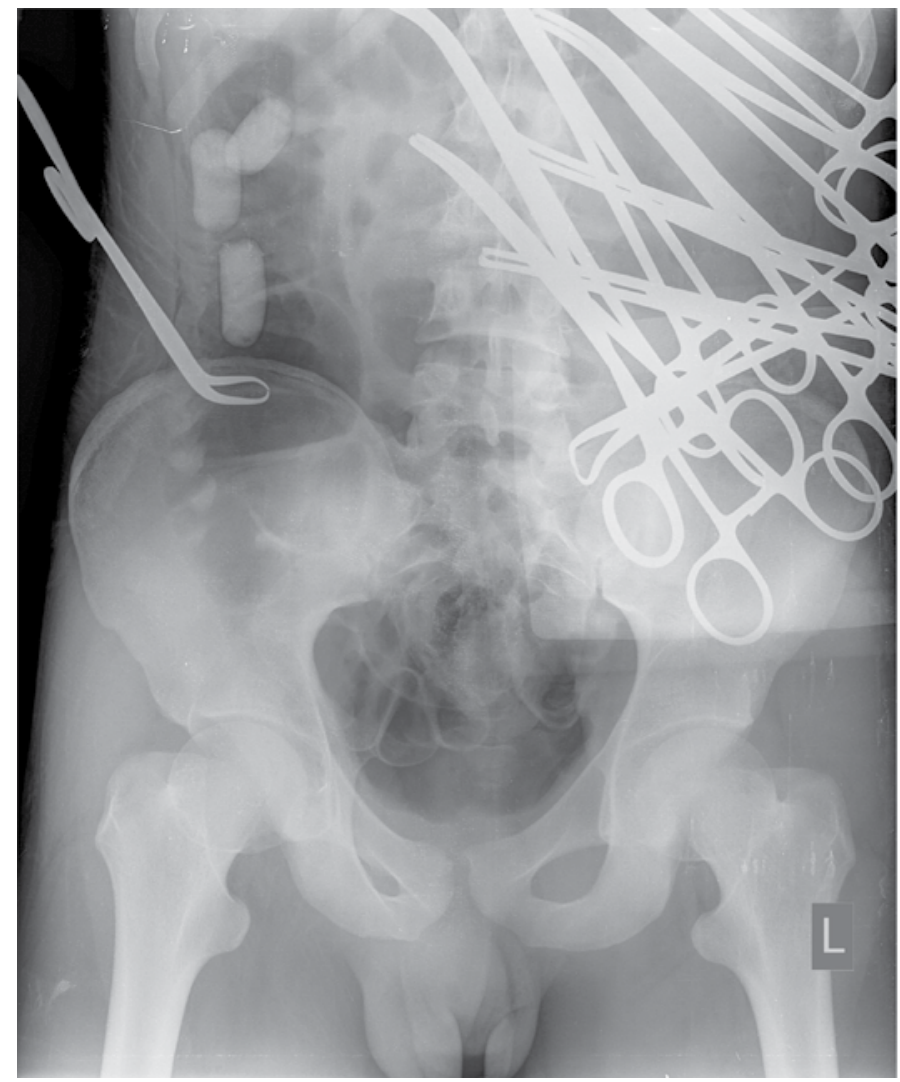

Рис. 3. Пациент Ш., 24 г. Рентгенограмма живота. В проекции восходящей ободочной кишки определяются 3 контейнера с героином (указано стрелкой).

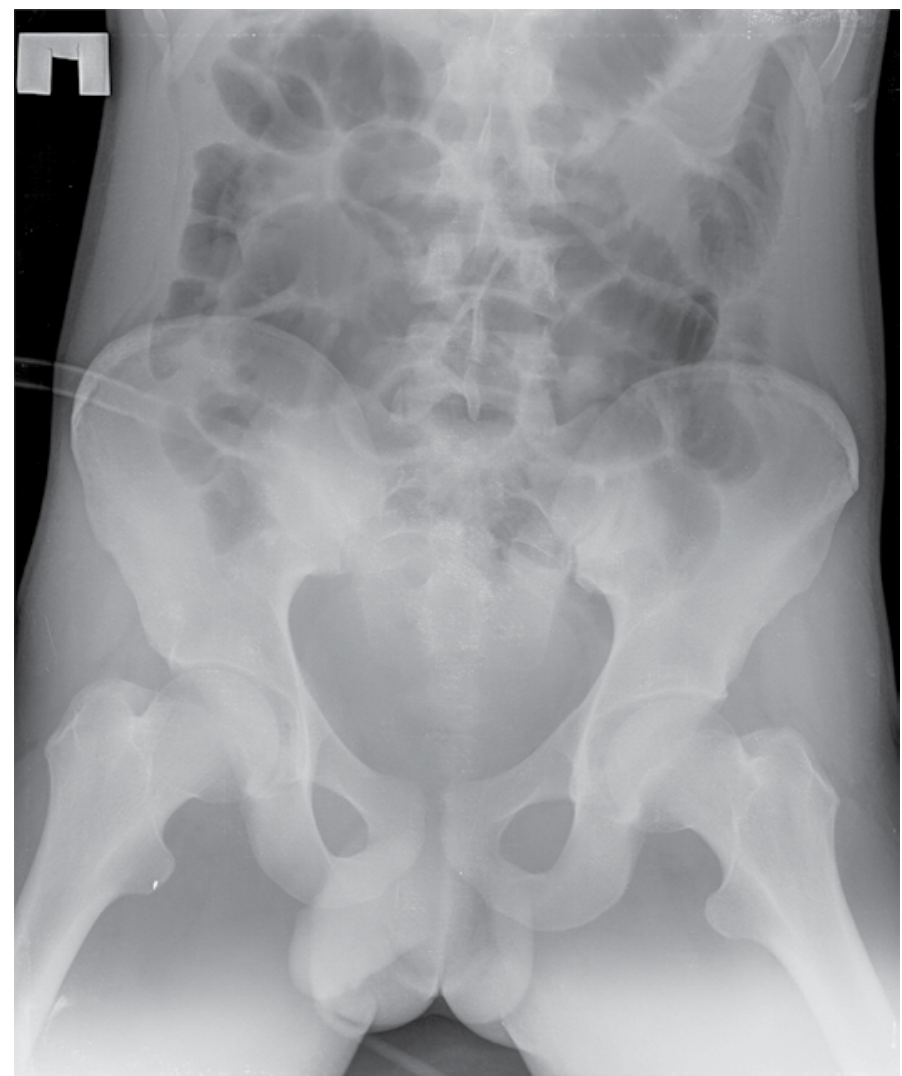

Рис. 4. Пациент Ш., 24 г. Рентгенограмма живота после удаления контейнеров с героином (контрольное исследование). Инородных тел в брюшной полости не выявлено. Дренаж в проекции малого таза. 
мм рт. ст.). Показатели активности системного воспаления оставались выше нормы до 3 суток после инцидента (лейкоциты 12,1 · 109/л, интерлейкин-6 до 95 пг/мл, интерлейкин-10 до 102 пг/ мл, С-реактивный белок до 49 мг/л, фибриноген до 5 г/л ).

Лечение острого отравления веществом наркотического действия с момента госпитализации проходило под контролем врача-токсиколога. При поступлении в качестве антидота больному Ш. внутривенно медленно в течение двух минут вводили раствор налоксона с начальной дозой 0,4 мг. Отсутствие эффекта потребовало повторного введения налоксона, которое проводили дважды внутривенно с интервалом от 3 до 5 минут до полного прояснения сознания и восстановления спонтанного дыхания. Общая доза вводимого налоксона составила 1,2 мг. Инфузионная терапия проводилась с целью снижения концентрации токсического вещества в плазме крови и включала водную нагрузку 5\% раствором глюкозы,
0,9\% физиологическим раствором, электролитов (объемом до 2,5 литров), лазикса. С целью профилактики гнойных осложнений, риск развития которых велик при таких выраженных лабораторных и клинических признаках системного воспаления, проведен курс антибиотикотерапии: введение антибиотика широкого спектра (ципрофлоксацин по 500 мг 2 раза в сутки) в сочетании с противомикробным препаратом (метронидазол 500 мг 2 раза в сутки) .

Пациент Ш. был выписан на 8-е сутки в удовлетворительном состоянии под наблюдение у хирурга.

Таким образом, у больного Ш. наблюдались классические клинические признаки острого отравления героином тяжелой степени, лабораторные показатели свидетельствовали о наличии синдрома системного воспалительного ответа. Особенности ведения пациента заключались в успешном сочетанном проведении токсикологических и хирургических методов лечения .

\section{СПИСОК ЛИТЕРАТУРЫ}

\begin{abstract}
1. Демчук С.Д., Харатишвили А.Г. Способы совершения контрабанды наркотических средств и психотропных веществ как элемент криминалистической характеристики этого вида преступлений. Вестник крими налистики; 2005; 3 (15): 93 - 99.
\end{abstract}

\section{REFERENCES:}

\begin{abstract}
1. Demchuk S.D., Kharatishvili A.G. The methods of committing smuggling of narcotic drugs and psychotropic substances as part of criminological characteristics of this type of crime. Vestnik kriminalistiki. 2005; 3 (15): 93 - 99 (in Russian).
\end{abstract}

2. Пятницкая И.Н. Общая и частная наркология. Руководство для врачей. М.: Медицина; 2008.

3. Лужников Е.А., Суходолова Г.Н. Острые отравления у взрослых и детей. М: ЭКСМО; 2009.

4. Лудевиг $P$. ., Лос $K$. Острые отрав-

2. Pyatnitskaya I.N. General and private drug and alcohol abuse. Guidelines for doctors - Moscow.: Meditsina; 2008 (in Russian)

3. Luzhnikov E.A., Sukhodolova G.N.

Acute poisoning in adults and children Moscow: EKSMO. 2009 (in Russian). ления: Пер. с нем. М.: Медицина; 1983.

5. Шилов В.В., Пивоварова Л.П., Лукин В.А, Малышев М.Е., Осипова И.В., Арискина О.Б. и др. Диагностика и прогнозирование тяжелого сепсиса у пациентов с острыми

4. Ludevig R., Los K. Acute poisoning: Trans. from German. Moscow: Meditsina; 1983 (in Russian). 5. Shilov V.V., Pivovarova L.P., Lukin V.A, Malyshev M.E., Osipova I.V., Ariskina 0.B. i dr. Diagnosis and prognosis of severe sepsis in patients отравлениями опиатами. Вопросы наркологии. 2012. 6: 28-34.

6. Teasdale G.M. Assessment of

coma and impaired consciousness. A practical scale. Lancet. 1974; 2 (2): $81-84$ with acute poisoning by opiates.

Voprosy narkologii. 2012; 6: 28-34. (in Russian).

6. Teasdale G.M. Assessment of coma and impaired consciousness. A practical scale. Lancet; 1974; 2 (2): $81-84$.

\section{V.V. Shilov', V.A. Lukin', V.E. Savello', A.M. Antonova ${ }^{2}$, L.P.Pivovarova ${ }^{2}$, I.V. Osipova², A.V. Rikova', S.S. Gaiduk ${ }^{2}$}

\section{CLINICAL OBSERVATION OF APATIENT -DRUG COURIER WITH ACUTE POISONING BY HEROIN}

${ }^{1}$ I.I. Mechnikov North-Western State Medical University, 195015, St. Petersburg, Russian Federation

2.I.Dzhanelidze Research Institute of Emergency Care, 192242, St. Petersburg, Russian Federation

A clinical observation of a patient, a drug courier. smuggling heroin in containers in gastric cavity is described. He was admitted to a multi-field hospital in consequence of acute poisoning. The acute poisoning resulted from a spontaneous violation of the container and outpouring of its content into the gastric cavity. At hospital, diagnostics and a combined treatment including surgical intervention and detoxification were carried out. Results of clinical, laboratory and instrumental investigations as well as treatment outcome are reported.

Keywords: heroin, systemic inflammation, surgical treatment. 